\title{
Association study between genetic variants and the risk of schizophrenia in the Chinese population based on GWAS- implicated 6p21.3-23.1 human genome region: a case-control study
}

\author{
Gangqin Li ${ }^{1}$, Jie Dai ${ }^{2}$, Hao Liu', Yushan Lin ${ }^{3}$, Qiaoni Liư ${ }^{3}$, Kaiyuan Zheng ${ }^{3}$, Suyu Li ${ }^{3}$, Siyu Chen ${ }^{4^{*}}$ and Yi Ye 5* $^{*}$
}

\begin{abstract}
Background: Schizophrenia is a polygenic disease; however, the specific risk genetic variants of schizophrenia are still largely unknown. Single nucleotide polymorphism (SNP) is important genetic factor for the susceptibility of schizophrenia. Investigating individual candidate gene contributing to disease risk remains important.

Methods: In a case-control study, five SNPs located in 6p21.3-p23.1 including rs2021722 in human leukocyte antigen (HLA) locus and rs107822, rs383711, rs439205 and rs421446 within the upstream of microRNA-219a-1 were genotyped in 454 schizophrenia patients and 445 healthy controls to investigate the possible association between the loci and schizophrenia in a Han Chinese population.

Results: Our results showed significant associations between the rs 2021722 and schizophrenia in allele (A vs. G: adjusted $\mathrm{OR}=1.661,95 \% \mathrm{Cl}=1.196-2.308$ ), co-dominant ( $\mathrm{AG}$ vs. $\mathrm{GG}$ : $\mathrm{OR}=1.760,95 \% \mathrm{Cl}=1.234-2.510$ ) and dominant genetic model (AG + AA vs. GG: $O R=1.756,95 \% \mathrm{Cl}=1.237-2.492)$, respectively. Haplotype analysis showed that TGGT and CAAC were protective factor for schizophrenia compared with TAAC haplotype $(\mathrm{OR}=0.324,95 \% \mathrm{Cl}=$ $0.157-0.672 ; \mathrm{OR}=0.423,95 \% \mathrm{Cl}=0.199-0.900)$.

Conclusions: These findings indicate that rs2021722 in HLA locus might be involved in pathogenesis of schizophrenia and that genotypes AG and allele A of the locus are risk factors for schizophrenia in the Han Chinese population, confirming the association between immune system and schizophrenia.
\end{abstract}

Keywords: Schizophrenia, Single nucleotide polymorphism, Human leukocyte antigen, miR-219a-1

\footnotetext{
* Correspondence: 745388106@qq.com; yeyiconan@163.com

${ }^{4}$ Nanchong Psychosomatic Hospital, Nanchong 637000, Sichuan, China

${ }^{5}$ Department of Forensic Toxicological Analysis, West China School of Basic

Medical Sciences \& Forensic Medicine, Sichuan University, Chengdu, Sichuan,

China

Full list of author information is available at the end of the article
}

(c) The Author(s). 2021 Open Access This article is licensed under a Creative Commons Attribution 4.0 International License, which permits use, sharing, adaptation, distribution and reproduction in any medium or format, as long as you give appropriate credit to the original author(s) and the source, provide a link to the Creative Commons licence, and indicate if changes were made. The images or other third party material in this article are included in the article's Creative Commons licence, unless indicated otherwise in a credit line to the material. If material is not included in the article's Creative Commons licence and your intended use is not permitted by statutory regulation or exceeds the permitted use, you will need to obtain permission directly from the copyright holder. To view a copy of this licence, visit http://creativecommons.org/licenses/by/4.0/. The Creative Commons Public Domain Dedication waiver (http://creativecommons.org/publicdomain/zero/1.0/) applies to the data made available in this article, unless otherwise stated in a credit line to the data. 


\section{Background}

Schizophrenia is a severe psychiatric disorder with a prevalence about $1 \sim 1.5 \%$ of the world population [1]. Interacting of multiple genetic, nutritional and environmental factors contributed to its etiology, while genetic factors provided basis for its susceptibility [2-4]. Although some investigations showed that genetic factors were the main causes of schizophrenia [5], the specific risk genetic variants of schizophrenia are still largely unknown. Recent genome-wide association studies (GWAS) indicated that schizophrenia was the result of hundreds or thousands of common genetic variants acting in concert to produce a neuropsychiatric phenotype [6]. Investigating individual candidate gene contributing to disease risks remains important. In 2011, the Schizophrenia Psychiatric Genome-Wide Association Study Consortium had reported the genome-wide association between the rs2021722 and schizophrenia in samples of European ancestry [7]. The rs2021722 is located within the human leukocyte antigen (HLA) locus on chromosome 6p21.3-23.1. This locus has been identified as one of the most robust genetic region susceptibility to schizophrenia based on European samples [8]. However, the association between the rs2021722 and schizophrenia has rarely been replicated in a large Han Chinese population. In this context, exploring the possible association between the rs2021722 and schizophrenia in Han Chinese population is in great need.

Although single nucleotide polymorphism (SNP) in coding genes plays an important role in the susceptibility to schizophrenia, it could not explain all of the genetic factors for schizophrenia. Therefore researchers began to focus on the effects of non-coding RNAs, especially microRNAs (miRNAs). miRNAs are small non-coding single stranded RNA molecules, which can regulate gene expression at the posttranscriptional level and in further, influence a great number of target genes and their functions. In recent years, accumulating evidence indicated that miRNAs may act as key regulators in a large number of different cellular processes, including neuronal proliferation and maturation, synaptogenesis and synaptic plasticity, dendrite and synaptic pruning $[9,10]$. These processes play crucial roles in mental health. It is evident that miRNAs offer an exciting potential not only to understand the underlying mechanisms of schizophrenia, but also for the future development of antipsychotics [11-13] .

miR-219a-1, located in the schizophrenia susceptible region of $6 \mathrm{p} 21.3$, is an important regulator in N-methylD-aspartate receptors (NMDAR)-mediated glutamate signal pathway $[14,15]$. This pathway is involved in synaptic plasticity and glutamatergic neurotransmission, and is regarded as the final common pathway on the road to schizophrenia [16]. Disruption of this signal pathway can lead to behavioral deficits, including schizophrenia [14]. Several lines of studies have suggested a link between miR-219a-1 dysregulation and NMDAR signaling in schizophrenia; however, the specific mechanism is still unknown. In this context, exploring the possible association between miR-219a-1 related SNPs and schizophrenia in Han Chinese population was the second aim of the present study.

In this study, we selected a GWAS identified schizophrenia-associated SNP rs2021722 in European population and aimed to investigate the possible association between the rs2021722 and schizophrenia in Han Chinese population. Considering the polygenetic nature of schizophrenia and the important role of miRNA for psychiatric disorders, we also selected SNPs within -2 $\mathrm{kb}$ of miR-219a-1 to investigate whether these SNPs were individually or jointly associated with schizophrenia in Han Chinese population.

\section{Methods \\ Participants}

A case-control study was performed in 454 clinical diagnosed schizophrenia patients (312 males, mean age $=$ $48.35 \pm 12.36$ years; 142 females: mean age $=47.20 \pm$ 12.10 years) and 445 healthy checking-up individuals (327males, mean age $=46.53 \pm 12.42$ years; 118 females: mean age $=47.83 \pm 12.74$ years) from January of 2019 to October of 2020 in Sichuan Province of China.

Schizophrenia patients were diagnosed by at least two psychiatrists according to the International Statistical Classification of Diseases and Related Health Problems, Tenth Revision (ICD-10) criteria. The controls were healthy checking-up individuals without any personal or family history of neuropsychiatric disorder or any abuse of addictive drug. All included participants were Han Chinese descendants. Peripheral blood sample $(2 \mathrm{ml})$ of each participant was collected in sterile tubes with EDTA-Na2 anticoagulants and stored at $-20^{\circ} \mathrm{C}$.

This study was approved by the Medical Ethics Committee of Sichuan University (reference number: K2018092) and written informed consents were obtained from all participants.

\section{SNPs selection and genotyping}

The rs2021722 was a GWAS identified schizophreniarelated SNP in European samples, which is of great value to be replicated in Han Chinese population. Except for the rs202121722, we also selected SNPs within $2 \mathrm{~kb}$ upstream of miR-219a-1, which is located in the schizophrenia susceptible region of $6 \mathrm{p} 21.3-23.1$. The criteria for SNPs selection were that minor allele frequency is more than $10 \%$ in Han Chinese population. Finally, four SNPs (i.e., rs107822, rs383711, rs439205 and rs421446) were enrolled in this study. 
Genomic DNA was extracted from the peripheral blood using Tiangen human blood genome isolation Kit (Tiangen, Beijing, China) according to the manufacturer's protocol. Genotypes of rs107822, rs383711and rs439205 were detected by TaqMan genotyping discrimination assay using ABI7500 PCR system (Applied Biosystems, Foster City, USA). Genotypes of rs2021722 and rs421446 were detected by polymerase chain reactionrestriction fragment length polymorphism (PCR-RFLP) assay. The primers of the rs2021722 were $5^{\prime}$-gtggggatttctagcgttca-3' (forward) and 5' -cccagtgactgtggatgatg-3' (reverse), which generated a 135-bp fragment. The fragment was then digested by AluI (New England BioLabs), and may produce three genotypes as GG (135 bp), AG (135, 76 and $59 \mathrm{bp})$, and $\mathrm{AA}(76$ and $59 \mathrm{bp})$. The primers for the rs421446 were 5 '-gccagactggacaccaagat3'(forward) and 5' - gtgacactccgggtcttctt-3' (reverse), which generated a 150-bp fragment. The fragment was then digested by Hpy888-III (New England BioLabs), and may produce three genotypes as CC (150 bp), CT (150, 130 and $20 \mathrm{bp}$ ), and TT(130 and $20 \mathrm{bp})$. Restriction fragments were distinguished on $8 \%$ polyacrylamide gel and visualized by silver staining to determine the genotypes. Negative control was used in each experiment and Sanger sequencing was done to confirm the genotyping result.

\section{Statistical analysis}

Genotype frequencies and Hardy-Weinberg equilibrium were calculated by SNPStats. Independent sample $t$-test was performed to compare the difference in quantitative data, while chi-square test was used to examine distribution difference of allele or genotype in two groups. Odds ratios (ORs) and 95\% confidence intervals (95\% CIs) were selected to estimate the strength between the five loci and risk of schizophrenia. All statistics were performed using SPSS software 17.0 (SPSS Inc., Chicago, IL, USA) and $p<0.05$ was considered as statistical significance.

\section{Results}

The genotype distributions of the five SNPs in the control group met the requirements of the Hardy-Weinberg equilibrium. Demographic information of the participants is present in Table 1 . There were no significant differences in age and gender distributions between patients and controls.

\section{The genotype and allele distributions}

The genotype and allele distributions of the five SNPs are present in Table 2. Among the five SNPs, only rs2021722 showed significant differences in allele and genotype frequencies between cases and controls. Frequencies of allele A $(\mathrm{OR}=1.661,95 \% \mathrm{CI}=1.196-2.308)$ and genotype $\mathrm{AG}(\mathrm{OR}=1.760,95 \% \mathrm{CI}=1.234-2.510)$ at the rs2021722 were higher in patient group than that in control group, suggesting that individuals carrying allele A could increase the risk of developing schizophrenia. No differences were observed in other four SNPs between cases and controls.

\section{Combined effects of the five SNPs}

We also examined the combined effects of rs2021722 and other four SNPs on schizophrenia risk. As shown in Table 3, the carriers with the combined genotypes of $\mathrm{rs} 2021722 \mathrm{AA} / \mathrm{AG}+\mathrm{rs} 107822 \mathrm{TT}(\mathrm{OR}=1.828,95 \% \mathrm{CI}=$ 1.096-3.048), $\quad \mathrm{rs} 2021722 \mathrm{AA} / \mathrm{AG}+\mathrm{rs} 107822 \mathrm{CC} / \mathrm{CT}$ $(\mathrm{OR}=1.957, \quad 95 \% \quad \mathrm{CI}=1.188-3.225), \quad \mathrm{rs} 2021722 \quad \mathrm{AA} /$ $\mathrm{AG}+\mathrm{rs} 383711 \quad \mathrm{GG} / \mathrm{AG} \quad(\mathrm{OR}=1.813, \quad 95 \% \quad \mathrm{CI}=1.141-$ 2.883), rs2021722 AA/AG + rs439205 GG/AG (OR = $1.773, \quad 95 \% \mathrm{CI}=1.093-2.876), \quad \mathrm{rs} 2021722 \quad \mathrm{AA} / \mathrm{AG}+$ rs421446 GG $(\mathrm{OR}=1.703,95 \% \mathrm{CI}=1.027-2.823)$ and rs2021722 AA/AG + rs421446 AA/AG (OR $=1.751,95 \%$ $\mathrm{CI}=1.065-2.878)$ had significant increased risk of schizophrenia.

\section{Linkage disequilibrium test and haplotype analysis of 4 SNPs within miR-219a-1}

The four SNPs (rs107822, rs383711, rs439205 and rs421446) located within $2 \mathrm{~kb}$ upstream of miR-219a-1 had strong linkage disequilibrium with each other (D ' =0.832-0.909, details are present in Table 4). We identified three protective haplotype blocks according to the pairwise linkage disequilibrium analysis (Table 5). Compared to TAAC, TGGT and CAAC acted as a risk haplotype $(\mathrm{OR}=0.324,95 \% \mathrm{CI}=$ $0.157-0.672 ; \quad \mathrm{OR}=0.423,95 \% \quad \mathrm{CI}=0.199-0.900$ ) for schizophrenia.

Table 1 Demographic characteristics of the included schizophrenia patients and healthy controls

\begin{tabular}{|c|c|c|c|c|c|c|c|}
\hline & \multicolumn{3}{|l|}{$H C^{a}$} & \multicolumn{3}{|l|}{$\mathrm{SCZ}$} & \multirow[t]{2}{*}{$p$} \\
\hline & Total & Male & Female & Total & Male & Female & \\
\hline Number & 445 & 327 & 118 & 454 & 312 & 142 & 0.115 \\
\hline Age $\left(M^{c} \pm S D^{d}\right)$ & $46.88( \pm 12.50)$ & $46.53( \pm 12.42)$ & $47.83( \pm 12.74)$ & $47.99( \pm 12.28)$ & $48.35( \pm 12.36)$ & $47.20( \pm 12.10)$ & 0.179 \\
\hline
\end{tabular}

Notes: ${ }^{\mathrm{a}} \mathrm{HC}=$ healthy controls; ${ }^{\mathrm{b}} \mathrm{SCZ}=$ schizophrenia patients; $\mathrm{M}^{\mathrm{c}}=$ Mean; $\mathrm{SD}^{\mathrm{d}}=$ Standard Deviation 
Table 2 The distribution of alleles and genotypes for 5 SNPs between schizophrenia patients and healthy control subjects

\begin{tabular}{|c|c|c|c|c|c|}
\hline & SNP & $\mathrm{HCs}^{\mathrm{a}}, \mathrm{N}^{\mathrm{b}}(\%)$ & $S C Z s^{c}, N(\%)$ & $\mathrm{OR}^{\mathrm{d}}\left(95 \% \mathrm{Cl}^{\mathrm{e}}\right)$ & $p$ \\
\hline \multicolumn{6}{|l|}{ rs107822 } \\
\hline & $\mathrm{T}$ & $569(63.9)$ & $564(62.1)$ & 1.000 (ref) & \\
\hline & C & $321(36.1) /(39.6)^{f}$ & $344(37.9)$ & $1.081(0.893-1.309)$ & 0.425 \\
\hline \multirow[t]{3}{*}{ codominant } & $\pi$ & $191(42.9)$ & $185(40.8)$ & 1.000 (ref) & \\
\hline & CC & $67(15.1)$ & $75(16.5)$ & $1.156(0.785-1.701)$ & 0.463 \\
\hline & $\mathrm{CT}$ & $187(42.0)$ & $194(42.7)$ & $1.071(0.805-1.424)$ & 0.637 \\
\hline \multirow[t]{2}{*}{ dominant } & $\pi$ & $191(42.9)$ & $185(40.8)$ & 1.000 (ref) & \\
\hline & $\mathrm{CC} / \mathrm{CT}$ & $254(57.1)$ & $269(59.2)$ & $1.093(0.839-1.425)$ & 0.509 \\
\hline \multirow[t]{2}{*}{ recessive } & $\Pi \mathrm{T}-\mathrm{CT}$ & $378(84.9)$ & $379(83.5)$ & 1.000 (ref) & \\
\hline & $\mathrm{CC}$ & $67(15.1)$ & $75(16.5)$ & $1.116(0.780-1.599)$ & 0.547 \\
\hline \multicolumn{6}{|l|}{ rs383711 } \\
\hline & A & $454(51.0)$ & $451(49.7)$ & 1.000 (ref) & 0.569 \\
\hline & G & $436(49.0) /(49.2)^{f}$ & $457(50.3)$ & $1.055(0.877-1.269)$ & \\
\hline \multirow[t]{3}{*}{ codominant } & AA & $114(25.6)$ & $112(24.7)$ & 1.000 (ref) & \\
\hline & $A G$ & $226(50.8)$ & $227(50.0)$ & $1.022(0.743-1.407)$ & 0.892 \\
\hline & GG & $105(23.6)$ & $115(25.3)$ & 1.115 (0.769-1.616) & 0.566 \\
\hline \multirow[t]{2}{*}{ dominant } & AA & $114(25.6)$ & $112(24.7)$ & 1.000 (ref) & \\
\hline & AG- GG & $331(74.4)$ & $342(75.3)$ & $1.052(0.778-1.422)$ & 0.743 \\
\hline \multirow[t]{2}{*}{ recessive } & $A A-A G$ & $340(76.4)$ & $339(74.7)$ & 1.000 (ref) & \\
\hline & GG & 105 (23.6) & $115(25.3)$ & $1.098(0.810-1.489)$ & 0.545 \\
\hline \multicolumn{6}{|l|}{ rs439205 } \\
\hline & A & $549(61.7)$ & $560(61.7)$ & 1.0000 (ref) & \\
\hline & G & $341(38.3) /(39.6)^{f}$ & $348(38.2)$ & $1.000(0.827-1.210)$ & 0.996 \\
\hline \multirow[t]{3}{*}{ codominant } & AA & $174(39.1)$ & $181(39.9)$ & 1.000 & \\
\hline & $A G$ & $201(45.2)$ & $198(43.6)$ & $0.947(0.711-1.261)$ & 0.709 \\
\hline & GG & $70(15.7)$ & $75(16.5)$ & $1.030(0.0 .700-1.516)$ & 0.881 \\
\hline \multirow[t]{2}{*}{ dominant } & AA & $174(39.1)$ & $181(39.9)$ & 1.000 (ref) & \\
\hline & AG- GG & $271(60.9)$ & $273(60.1)$ & $0.968(0.741-1.265)$ & 0.814 \\
\hline \multirow[t]{2}{*}{ recessive } & $A A-A G$ & $375(84.3)$ & $379(83.5)$ & 1.000 (ref) & 0.748 \\
\hline & GG & $70(15.7)$ & $75(16.5)$ & $1.060(0.743-1.513)$ & \\
\hline \multicolumn{6}{|l|}{ rs2021722 } \\
\hline & G & $827(92.9)$ & $806(88.8)$ & 1.000 (ref) & \\
\hline & $A$ & $63(7.1) /(10.9)^{f}$ & $102(11.2)$ & $1.661(1.196-2.308)$ & 0.002 \\
\hline \multirow[t]{3}{*}{ codominant } & GG & $384(86.3)$ & $355(78.2)$ & 1.000 (ref) & \\
\hline & $\mathrm{AA}$ & $2(0.4)$ & $3(0.7)$ & $1.623(0.270-9.767)$ & 0.933 \\
\hline & $A G$ & 59 (13.3) & $96(21.1)$ & $1.760(1.234-2.510)$ & 0.002 \\
\hline \multirow[t]{2}{*}{ dominant } & GG & $384(86.3)$ & $355(78.2)$ & 1.000 (ref) & \\
\hline & AG-AA & $61(13.7)$ & 99 (21.8) & 1.756 (1.237-2.492) & 0.002 \\
\hline \multirow[t]{2}{*}{ recessive } & GG-AG & 443 (99.5) & $451(99.3)$ & 1.000 (ref) & 0.670 \\
\hline & AA & $2(0.4)$ & $3(0.7)$ & $1.473(0.245-8.860)$ & \\
\hline \multicolumn{6}{|l|}{ rs421446 } \\
\hline & G & $598(67.2)$ & $607(66.8)$ & 1.000 (ref) & \\
\hline & A & $292(32.8) /(38.3)^{f}$ & $301(33.1)$ & $1.016(0.834-1.236)$ & 0.878 \\
\hline codominant & GG & $196(44.0)$ & $204(44.9)$ & 1.000 (ref) & \\
\hline
\end{tabular}


Table 2 The distribution of alleles and genotypes for 5 SNPs between schizophrenia patients and healthy control subjects (Continued)

\begin{tabular}{|c|c|c|c|c|c|}
\hline & SNP & $\mathrm{HCs}^{\mathrm{a}}, \mathrm{N}^{\mathrm{b}}(\%)$ & $S C Z s^{c}, N(\%)$ & $\mathrm{OR}^{\mathrm{d}}\left(95 \% \mathrm{Cl}^{\mathrm{e}}\right)$ & $p$ \\
\hline & $A G$ & $206(46.3)$ & 199 (43.8) & $0.928(0.704-1.224)$ & 0.597 \\
\hline & AA & $43(9.7)$ & $51(11.2)$ & $1.140(0.726-1.788)$ & 0.570 \\
\hline \multirow[t]{2}{*}{ dominant } & GG & $196(44.0)$ & $204(44.9)$ & 1.000 (ref) & \\
\hline & $A G-A A$ & $249(56.0)$ & $250(55.1)$ & $0.965(0.741-1.255)$ & 0.789 \\
\hline \multirow[t]{2}{*}{ recessive } & GG- AG & $402(90.3)$ & $403(88.8)$ & 1.000 (ref) & \\
\hline & AA & $43(9.7)$ & $51(11.2)$ & $1.183(0.771-1.816)$ & 0.442 \\
\hline
\end{tabular}
the slash is minor allele frequency in East Asian sample (EAS), data are based on NCBI SNPdatabase (http://www.ncbi.nlm.nih.gov/snp/; accessed on 10 June 2021)

Expression quantitative trait loci (eQTL) analysis of the 4 SNPs within miR-219a-1

Expression Quantitative trait loci (eQTL) analysis showed that all the four SNPs within miR-219a-1 are associated with HLA-DPB2 and would significantly influence the expression of HLA-DPB2(all $p<0.001$ ) in whole blood (see details in Fig. 1).

\section{Discussion}

In this case-control study, we investigated the association between five SNPs on the chrome 6 (6p21-22) and the risk of schizophrenia in a Han Chinese population. In consistent with the GWAS findings in European samples [7], we found that the rs2021722 in HLA locus was also associated with the risk of schizophrenia in our Han Chinese population. Subjects carrying rs2021722 AG genotype and A allele had increased risk of schizophrenia.

The rs2021722 is located within the HLA locus that was identified as one of the most significant determinant of schizophrenia susceptibility in GWAS [17, 18]. Emerging evidence has indicated that immune system and central nervous system (CNS) may have common evolutionary origin and interact with each other in many pathways [19, 20]. Schizophrenia has been extensively studied to be abnormal in immune systems [21], for example, several meta-analysis have reported that immune system was over active in patients with medication-naive

Table 3 The combined genotypes frequencies of rs2021722 with other four SNPs in two groups

\begin{tabular}{|c|c|c|c|c|}
\hline Polymorphisms & HCs, N (\%) & SCZs, N (\%) & OR $(95 \% \mathrm{Cl})$ & $p$ \\
\hline \multicolumn{5}{|l|}{ rs2021722 \& rs107822 } \\
\hline rs2021722 GG + rs107822 Tा & $161(36.2)$ & $138(30.4)$ & 1.000 (ref) & \\
\hline rs2021722 GG + rs107822 CC/CT & $223(50.1)$ & $217(47.8)$ & $1.135(0.846-1.524)$ & 0.398 \\
\hline rs2021722 AA/AG + rs107822 Tा & $30(6.7)$ & $47(10.4)$ & $1.828(1.096-3.048)$ & 0.020 \\
\hline rs2021722 AA/AG + rs107822 CC/CT & $31(7.0)$ & $52(11.5)$ & $1.957(1.188-3.225)$ & 0.008 \\
\hline \multicolumn{5}{|l|}{ rs2021722 \& rs383711 } \\
\hline rs2021722 GG + rs383711AA & $100(22.5)$ & $88(19.4)$ & 1.000 (ref) & \\
\hline rs2021722 GG + rs383711 GG/AG & $284(63.8)$ & $267(58.8)$ & $1.068(0.767-1.488)$ & 0.696 \\
\hline rs2021722 AA/AG + rs383711 AA & $14(3.1)$ & $24(5.3)$ & $1.948(0.949-3.997)$ & 0.066 \\
\hline rs2021722 AA/AG + rs383711 GG/AG & 47 (10.6) & $75(16.5)$ & $1.813(1.141-2.883)$ & 0.012 \\
\hline \multicolumn{5}{|l|}{ rs2021722 \& rs439205 } \\
\hline rs2021722 GG + rs439205 AA & $147(33.0)$ & $139(30.6)$ & 1.000 (ref) & \\
\hline rs2021722 GG + rs439205 GG/AG & $237(53.3)$ & $216(47.6)$ & $0.964(0.717-1.296)$ & 0.808 \\
\hline rs2021722 AA/AG + rs439205 AA & $27(6.1)$ & $42(9.3)$ & $1.645(0.962-2.812)$ & 0.067 \\
\hline rs2021722 AA/AG + rs439205GG/AG & $34(7.6)$ & $57(12.6)$ & $1.773(1.093-2.876)$ & 0.020 \\
\hline \multicolumn{5}{|l|}{ rs2021722 \& rs421446 } \\
\hline rs2021722 GG + rs421446 GG & $166(37.3)$ & $156(34.4)$ & 1.000 (ref) & \\
\hline rs2021722 GG + rs421446 AA/AG & $218(49.0)$ & $199(43.8)$ & $0.971(0.726-1.299)$ & 0.845 \\
\hline rs2021722 AA/AG + rs421446 GG & $30(6.7)$ & $48(10.6)$ & $1.703(1.027-2.823)$ & 0.038 \\
\hline rs2021722 AA/AG + rs421446 AA/AG & $31(7.0)$ & $51(11.2)$ & $1.751(1.065-2.878)$ & 0.026 \\
\hline
\end{tabular}


Table 4 Linkage disequilibrium tests of four SNPs within miR-219a-1

\begin{tabular}{|c|c|c|c|c|}
\hline & rs107822, $D^{\prime}\left(r^{2}\right)$ & rs383711, D'(r) & rs439205, D'(r) & rs421446, $D^{\prime}(r)$ \\
\hline rs107822 & - & $0.895(0.439)$ & $0.849(0.681)$ & $0.832(0.580)$ \\
\hline rs383711 & $0.895(0.439)$ & - & $0.887(0.495)$ & $0.909(0.412)$ \\
\hline rs439205 & $0.849(0.681)$ & $0.887(0.495)$ & - & $0.884(0.619)$ \\
\hline rs421446 & $0.832(0.580)$ & $0.909(0.412)$ & $0.884(0.619)$ & - \\
\hline
\end{tabular}

first episode psychosis [22-24]. Immune dysfunctions may affect neurobiological circuits including changed neurotransmitter metabolisms contributing to pathophysiological alterations in schizophrenia [23]. Another line of evidence suggested the imbalance between type-1 and type- 2 immune responses of schizophrenia might lead to the glutamatergic-dopaminergic dysregulation and then contribute to the clinical symptoms of psychosis [22].

Except the immunological function, increasing evidence has shown that HLA proteins have fundamental non-immune effect in neurogenesis, neuronal differentiation and migration, synaptogenesis, synaptic plasticity and pruning [25-27]. These processes have all been involved in the pathogenesis of schizophrenia [28, 29]. CNS structure integrity(e.g. enlarged ventricles) was one of the frequently reported structural abnormalities in schizophrenic patients and animal models [30, 31]. Tao et al. reported that the rs2021722 was significantly associated with cortical thickness in antipsychotic-naïve schizophrenia patients, indicating that the immune system may play critical roles in the pathology of schizophrenia via the modulation of the development of cerebral cortical structures [32]. Together, although the specific mechanism of interaction between immune system and schizophrenia is not fully known, the present study confirmed the association between the rs2021722 in the HLA region and the risk of schizophrenia in Han Chinese population. Mechanisms on how genetic

Table 5 Haplotype analysis of four SNPs within miR-219a-1 between two groups

\begin{tabular}{lllll}
\hline & HCs, N(\%) & SCZs, $\mathbf{N}(\%)$ & OR (95\% Cl) & $\boldsymbol{p}$ \\
\hline TAAC & $402(45.2)$ & $413(45.5)$ & $1.000($ ref $)$ & - \\
CGGT & $237(26.6)$ & $269(29.6)$ & $1.105(0.885-1.380)$ & 0.379 \\
TGAC & $96(10.8)$ & $115(12.7)$ & $1.166(0.861-1.580)$ & 0.321 \\
CGGC & $38(4.3)$ & $50(5.5)$ & $1.281(0.822-1.996)$ & 0.273 \\
TGGT & $30(3.4)$ & $10(1.1)$ & $0.324(0.157-0.672)$ & 0.002 \\
CAAC & $23(2.6)$ & $10(1.1)$ & $0.423(0.199-0.900)$ & 0.022 \\
TAGC & $18(2.0)$ & $10(1.1)$ & $0.541(0.247-1.186)$ & 0.120 \\
TAAT & $6(0.7)$ & $10(1.1)$ & $1.622(0.584-4.505)$ & 0.349 \\
CGAT & $12(1.3)$ & $5(0.5)$ & $0.406(0.142-1.162)$ & 0.083 \\
TGGC & $12(1.4)$ & $5(0.5)$ & $0.406(0.142-1.162)$ & 0.083 \\
\hline
\end{tabular}

Notes: ${ }^{a} \mathrm{HC}$ Healthy controls, ${ }^{b} \mathrm{~N}$ number of the group, ${ }^{\mathrm{C}} \mathrm{SCZ}$ Schizophrenia patient, ${ }^{\mathrm{d}} \mathrm{OR}$ Odds ratio, ${ }^{\mathrm{e}} \mathrm{Cl}$ Confidence interval variability like rs2021722 in HLA region leads to schizophrenia are worthy of further investigation.

miR-219a-1, located in the schizophrenia susceptible region of $6 \mathrm{p} 21.3$, has important role in the structure and function of CNS. It could inhibit NMDA signaling by attenuating NMDA-induced neuronal depolarization and is an important regulator in NMDA receptors-mediated glutamate signal pathway [33]. The glutamate pathway is involved in synaptic plasticity and glutamatergic neurotransmission, and was regarded as the final common pathway on the road to schizophrenia [16]. Except the effect on NMDA signal pathway, miR-219a-1 was also reported to positively regulate oligodendrocyte differentiation, myelin and maturation $[34,35]$, and play a role in circadian rhythm [33]. These processes mentioned above are all involved with pathogenesis of schizophrenia, indicating that the association between miR-219a-1 and schizophrenia. Four SNPs (rs107822, rs383711, rs439205 and rs421446) within $2 \mathrm{~kb}$ upstream of miR219a-1 were selected in the current study to explore their associations with schizophrenia. eQTL analysis showed that all the four SNPs within miR-219a-1 could significantly influence the expression of HLA-DPB2. HLA-DPB2 is a pseudogene located in HLA region, which is strongly relevant to immune-related biological functions (e.g. adaptive immune response) by influencing the expression and activation of immune cells such as monocytes, NK cell and T cell [36]. In light of the association between immune system and schizophrenia, it might speculate that these four SNPs have some potential association with the pathogenesis of schizophrenia. Sun et al. had reported that the rs107822 within miR219a-1 was significantly associated with the risk of schizophrenia and genotypes TC/CC and allele $\mathrm{C}$ of the locus may be used as predictive factors for the etiology of schizophrenia [37]. Zhang et al. also found that rs107822 within miR-219a-1 was nominally associated with schizhophrenia [15]. However, we failed to find any difference of the four SNPs within $2 \mathrm{kp}$ upstream of miR219a-1 between schizophrenia patients and healthy controls in the current study. Samples from different geographical area and relatively small sample size may account for the differences due to heterogeneity [38]. Further studies with larger sample size are required to investigate the association between miR-219 and related SNPs and schizophrenia. 


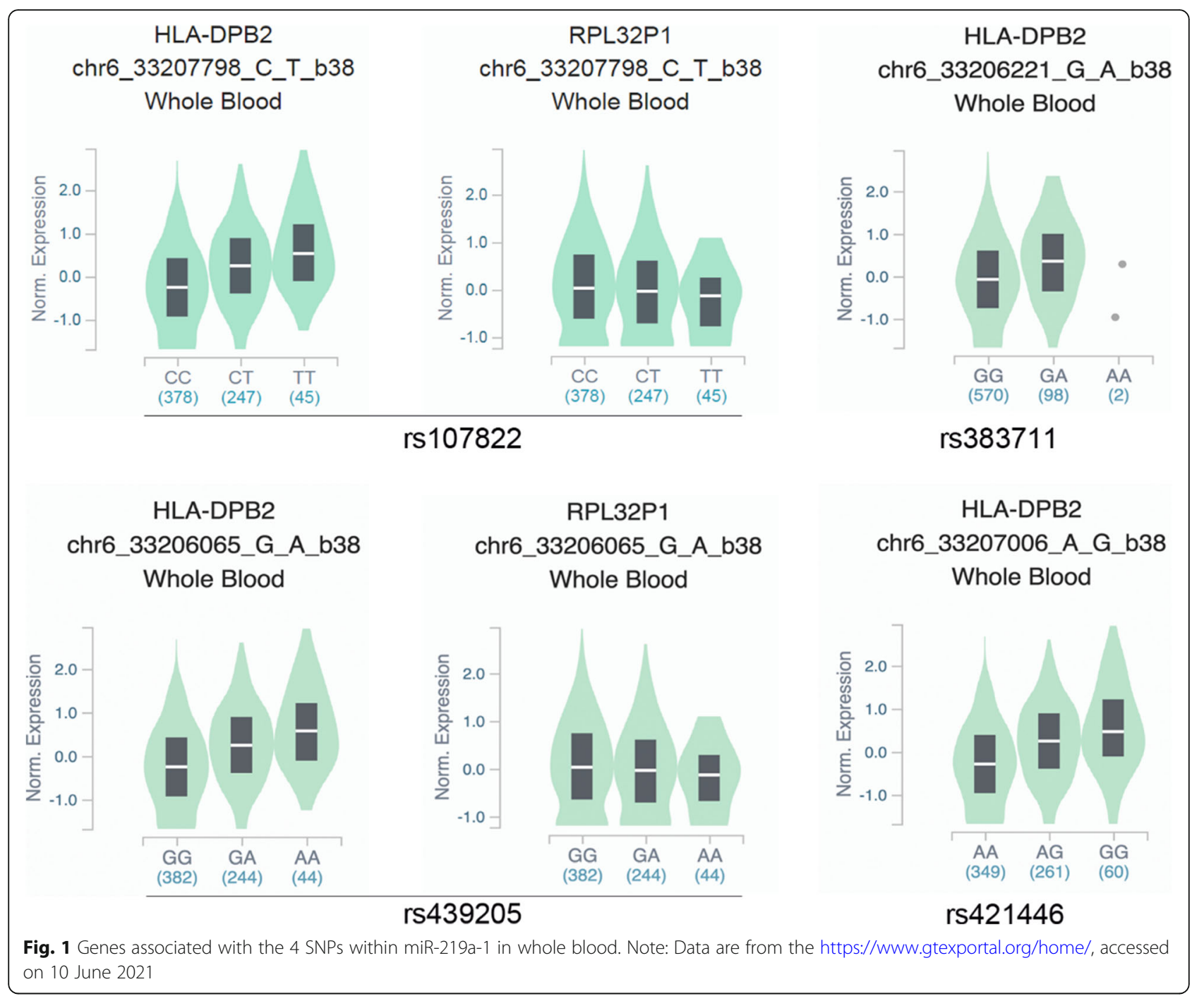

In order to investigate the interaction effect of the rs2021722 and other four SNPs on schizophrenia, combined analysis was performed in our study. The results showed that there was significantly combined effect of the rs2021722 and other four SNPs within miR-219a-1 on the risk of schizophrenia. Subjects carrying genotypes of rs2021722 AA/AG combined with any other four SNPs (rs107822 TT, rs107822 CC/CT, rs383711 GG/ AG, rs439205GG/AG, rs421446 GG and rs421446 AA/ AG) had an increased risk of schizophrenia. Smrt et al. had reported that miR-137 regulated neuronal maturation by targeting ubiquitin ligase Mind Bomb-1 [39]. The rs2021722 is an intron variant in Tripartite motif (TRIM), and most of the TRIM family proteins have E3 ubiquitin ligase activities with various functions including apoptosis, autophagy, innate immunity, and carcinogenesis [40]. This finding suggests that miR-137 may interact with the rs2021722 and jointly contribute to schizophrenia. It is worthy of further study to test whether there is corporation between miR-219a-1 and the rs2021722 in TRIM 26 for the pathogenesis of schizophrenia.

In the end, there still have some limitations in our study. Firstly, the sample size was relatively small, and only Han Chinese population was included. Further studies with larger sample size and multiple ethnic populations are needed to replicate our findings. Secondly, the current study had only five SNPs included, future studies could enroll additional potential functional SNPs affecting the expression of HLA and miR-219 to investigate the potential causal effects on schizophrenia under the framework of Mendelian Randomization analysis [41-43], and we may construct machine learning models to assist early diagnosis of schizophrenia based on these associated genetic variants $[44,45]$.

In conclusion, our study showed that the rs2021722 was associated with susceptibility to schizophrenia in Han Chinese population and genotype AG and allele A 
in this locus may be used as risk genetic markers for the disorder. Additionally, the results also indicated the potential interaction effects of the rs2021722 and other four SNPs within miR-219a-1 on the risk of schizophrenia. The specific mechanisms of these five SNPs on schizophrenia are worthy of future investigation. These findings might provide tools for better diagnostic and therapeutic characterization of schizophrenia.

\begin{abstract}
Abbreviations
SNP: Single nucleotide polymorphism; miRNA: Micro ribonucleic acid; GWAS: Genome-wide association study; HLA: Human leukocyte antigen; TRIM: Tripartite motif; CNS: Central nervous system; NMDAR: N-methyl-Daspartate receptors; ICD-10: International Statistical Classification of Diseases and Related Health Problems-Tenth Revision; HC: Healthy controls; SCZ: Schizophrenia patient; OR: Odds ratio; Cl: Confidence interval; SD: Standard deviation
\end{abstract}

\section{Acknowledgements}

Not applicable.

\section{Authors' contributions}

GQL designed the whole study, performed the experiments; analyzed and interpreted the data, and was a major contributor in writing the manuscript; JD, HL, YSL, QNL, KYZ, SYL performed the experiments; SYC collected the clinical information and blood samples of the subjects, analyzed and interpreted the data; $Y Y$ designed the study and performed the experiments. The author(s) read and approved the final manuscript.

\section{Funding}

This research was funded by China Postdoctoral Science Foundation (2018 M643488) and National Natural Science Foundation of China (81901928).

\section{Availability of data and materials}

The data-sets used and/or analyzed during the current study available from the corresponding author on reasonable request.

\section{Declarations}

\section{Ethics approval and consent to participate}

This study was approved by the Medical Ethics Committee of Sichuan University (reference number: K2018092), and all the methods and procedures were carried out in accordance with relevant guidelines and regulations. Written informed consents were obtained from all participants.

\section{Consent for publication}

All the authors consent to the publication of this article.

\section{Competing interests}

The authors declare that they have no competing interests.

\begin{abstract}
Author details
'Department of Forensic Psychiatry, West China School of Basic Medical Sciences \& Forensic Medicine, Sichuan University, Chengdu 610041, Sichuan, China. ${ }^{2}$ Department of Pathology, Sichuan Cancer Hospital, Chengdu, Sichuan, China. ${ }^{3}$ West China School of Basic Medical Sciences \& Forensic Medicine, Sichuan University, Chengdu, Sichuan, China. ${ }^{4}$ Nanchong Psychosomatic Hospital, Nanchong 637000, Sichuan, China. ${ }^{5}$ Department of Forensic Toxicological Analysis, West China School of Basic Medical Sciences \& Forensic Medicine, Sichuan University, Chengdu, Sichuan, China.
\end{abstract}

Received: 19 April 2021 Accepted: 20 September 2021

Published online: 04 October 2021

\section{References}

1. GBD 2017 Disease and Injury Incidence and Prevalence Collaborators. Global, regional, and national incidence, prevalence, and years lived with disability for 354 diseases and injuries for 195 countries and territories,
1990-2017: a systematic analysis for the Global Burden of Disease Study 2017. Lancet. 2018;392(10159):1789-858.

2. Yan X, Zhao X, Li J, He L, Xu M. Effects of early-life malnutrition on neurodevelopment and neuropsychiatric disorders and the potential mechanisms. Prog Neuro-Psychopharmacol Biol Psychiatry. 2018;20(83):6475. https://doi.org/10.1016/.jpnpbp.2017.12.016.

3. Chen J, Zhao X, Cui L, He G, Wang X, Wang F, et al. Genetic regulatory subnetworks and key regulating genes in rat hippocampus perturbed by prenatal malnutrition: implications for major brain disorders. Aging (Albany NY). 2020;12(9):8434-58. https://doi.org/10.18632/aging.103150.

4. Wang X, Jiao X, Tian Y, Zhang J, Zhang Y, Li J, et al. Shanghai birth cohort study. Associations between maternal vitamin D status during three trimesters and cord blood 25(OH) D concentrations in newborns: a prospective Shanghai birth cohort study. Eur J Nutr. 2021;60(6):3473-83. https://doi.org/10.1007/s00394-021-02528-w.

5. Jv O, Kapur S. Schizophrenia. Lancet. 2009;374(9690):635-45. https://doi. org/10.1016/S0140-6736(09)60995-8.

6. Wu Y, Cao H, Baranova A, Huang H, Li S, Cai L, et al. Multi-trait analysis for genome-wide association study of five psychiatric disorders. Transl Psychiatry. 2020;10(1):209. https://doi.org/10.1038/541398-020-00902-6.

7. Schizophrenia Psychiatric Genome-Wide Association Study Consorttium. Genome-wide association study identifies five new schizophrenia loci. Nat Genet. 2011:43(10):969-76. https://doi.org/10.1038/ng.940.

8. Aberg KA, Liu Y, Bukszar J, McClay JL, Khachane AN, Andreassen OA, et al. A comprehensive family-based replication study of schizophrenia genes. JAMA Psychiatry. 2013;70(6):573-81. https://doi.org/10.1001/jamapsychiatry.2 013.288.

9. Li H, Wang X, Lu X, Zhu H, Li S, Duan S, et al. Co-expression network analysis identified hub genes critical to triglyceride and free fatty acid metabolism as key regulators of age-related vascular dysfunction in mice. Aging (Albany NY). 2019;11(18):7620-38. https:/doi.org/10.18632/aging.102275.

10. Geaghan M, Cairns MJ. Small RNA dysregulation in neurocognitive and neuropsychiatric disorders. In: Geaghan M, Cairns MJ, editors. Small RNA dysregulation in neurocognitive and neuropsychiatric disorders. Cambridge: Academic Press; 2017

11. Cao T, Zhen XC. Dysregulation of miRNA and its potential therapeutic application in schizophrenia. CNS Neurosci Ther. 2018;24(7):586-97. https:// doi.org/10.1111/cns.12840

12. Hunsberger JG, Austin DR, Chen G, Manji HK. MicroRNAs in mental health: from biological underpinnings to potential therapies. NeuroMolecular Med. 2009;11(3):173-82. https://doi.org/10.1007/s12017-009-8070-5.

13. Bravo JA, Dinan TG. MicroRNAs: a novel therapeutic target for schizophrenia. Curr Pharm Des. 2011;17(2):176-88. https://doi.org/10.2174/13816121179504 9543.

14. Kocerha J, Faghihi MA, Lopez-Toledano MA, Huang J, Ramsey AJ, Caon MG, et al. MicroRNA-219 modulates NMDA receptor-mediated neurobehavioral dysfunction. PNAS. 2009;106(9):3507-12. https://doi.org/10.1073/pnas. 0805854106.

15. Zhang Y, Fan M, Wang Q, He G, Fu Y, Li H, et al. Polymorphisms in microRNA genes and genes involving in NMDAR signaling and schizophrenia: a case-control study in Han Chinese population. Sci Rep. 2015;5(1):12984. https://doi.org/10.1038/srep12984.

16. Kantrowitz JT, Javitt DC. N-methyl-d-aspartate (NMDA) receptor dysfunction or dysregulation: the final common pathway on the road to schizophrenia? Brain Res Bull. 2010;83(3-4):108-21. https://doi.org/10.1016/j.brainresbull.201 0.04.006.

17. Stefansson H, Ophoff RA, Steinberg S, Andreassen OA, Cichon S, Rujescu D, et al. Common variants conferring risk of schizophrenia. Nature. 2009; 460(7256):744-7. https://doi.org/10.1038/nature08186.

18. Shi J, Levinson DF, Duan J, Sanders AR, Zheng Y, Pe'er I, et al. Common variants on chromosome 6p22.1 are associated with schizophrenia. Nature. 2009;460(7256):753-7. https://doi.org/10.1038/nature08192.

19. McAllister AK, van de Water J. Breaking boundaries in neural-immune interactions. Neuron. 2009;64(1):9-12. https://doi.org/10.1016/j.neuron.2009. 09.038.

20. Kipnis J. Multifaceted interactions between adaptive immunity and the central nervous system. Science. 2016;353(6301):766-71. https://doi.org/1 $0.1126 /$ science.aag2638.

21. Muller N, Riedel M, Gruber R, Ackenheil M, Schwarz MJ. The immune system and schizophrenia. An integrative view. Ann N Y Acad Sci. 2000;917:456-67. https://doi.org/10.1111/j.1749-6632.2000.tb05410.x. 
22. Miuller N, Schwarz MJ. The immunological basis of glutamatergic disturbance in schizophrenia: towards an integrated view. J Neural Transm Suppl. 2007;72:269-80. https://doi.org/10.1007/978-3-211-73574-9_33.

23. Zheng S, Zhao T, Yuan S, Yang L, Ding J, Cui L, et al. Immunodeficiency promotes adaptive alterations of host gut microbiome: An observational metagenomic study in mice. Front Microbiol. 2019;10:2415. https://doi.org/1 0.3389/fmicb.2019.02415

24. Upthegrove R, Manzanares-Teson N, Barnes NM. Cytokine function in medication-naive first episode psychosis: a systematic review and metaanalysis. Schizophr Res. 2014;155(1-3):101-8. https://doi.org/10.1016/j. schres.2014.03.005

25. Shatz CJ. MHC class I: An unexpected role in neuronal plasticity. Neuron 2009;64(1):40-5. https://doi.org/10.1016/j.neuron.2009.09.044.

26. Glynn MW, Elmer BM, Garay PA, Liu XB, Needleman LA, El-Sabeawy F, et al. $\mathrm{MHCl}$ negatively regulates synapse density during the establishment of cortical connections. Nat Neurosci. 2011;14(4):442-51. https://doi.org/10.103 8/nn.2764.

27. Goddard CA, Butts DA, Shatz CJ. Regulation of CNS synapses by neuronal MHC class I. Proc Natl Acad Sci U S A. 2007;104(16):6828-33. https://doi. org/10.1073/pnas.0702023104.

28. Balu DT, Coyle JT. Neuroplasticity signaling pathways linked to the pathophysiology of schizophrenia. Neurosci Biobehav Rev. 2011;35(3):84870. https://doi.org/10.1016/j.neubiorev.2010.10.005.

29. Stephan KE, Baldeweg T, Friston KJ. Synaptic plasticity and dysconnection in schizophrenia. Biol Psychiatry. 2006;59(10):929-39. https://doi.org/10.1016/j. biopsych.2005.10.005.

30. Allen AJ, Griss ME, Folley BS, Hawkins KA, Pearlson GD. Endophenotypes in schizophrenia: a selective review. Schizophr Res. 2009;109(1-3):24-37. https://doi.org/10.1016/j.schres.2009.01.016.

31. Huh GS, Boulanger LM, Du H, Riquelme PA, Brotz TM, Shatz CJ. Functional requirement for class I MHC in CNS development and plasticity. Science. 2000:290(5499):2155-9. https://doi.org/10.1126/science.290.5499.2155.

32. Tao B, Xiao Y, Hu N, Shah C, Liu L, Gao X, et al. Reduced cortical thickness related to single nucleotide polymorphisms in the major histocompatibility complex region in antipsychotic-naive schizophrenia. Brain Behav. 2019;9(5): e01253. https://doi.org/10.1002/brb3.1253.

33. Cheng HY, Papp JW, Varlamova O, Dziema H, Russell B, Curfman JP, et al. microRNA modulation of circadian-clock period and entrainment. Neuron. 2007;54(5):813-29. https://doi.org/10.1016/j.neuron.2007.05.017.

34. Zhou X, Li Q, Xu J, Zhang X, Zhang H, Xiang Y, et al. The aberrantly expressed miR-193b-3p contributes to preeclampsia through regulating transforming growth factor- $\beta$ signaling. Sci Rep. 2016;6(1):19910. https://doi. org/10.1038/srep19910.

35. Jin G, Xu M, Zou M, Duan S. The processing, gene regulation, biological functions, and clinical relevance of N4-Acetylcytidine on RNA: a systematic review. Mol Ther Nucleic Acids. 2020;20:13-24. https://doi.org/10.1016/j. omtn.2020.01.037.

36. Lyu L, Yao J, Wang M, Zheng Y, Xu P, Wang S, et al. Overexpressed pseudogene HLA-DPB2 promotes tumor immune infiltrates by regulating HLA-DPB1 and iindicates a better prognosis in breast cancer. Front Oncol. 2020;10:1245. https://doi.org/10.3389/fonc.2020.01245.

37. Sun YJ, Yu Y, Zhu GC, Sun ZH, Xu J, Cao JH, et al. Association between single nucleotide polymorphisms in MiR219-1 and MiR137 and susceptibility to schizophrenia in a Chinese population. FEBS Open Bio. 2015;5(1):774-8. https://doi.org/10.1016/j.fob.2015.08.008.

38. Jiang L, Wang K, Lo K, Zhong Y, Yang A, Fang X, et al. Sex-specific association of circulating ferritin level and risk of type 2 diabetes: a doseresponse meta-analysis of prospective studies. J Clin Endocrinol Metab. 2019;104(10):4539-51. https://doi.org/10.1210/jc.2019-00495.

39. Smrt RD, Szulwach KE, Pfeiffer RL, Li X, Guo W, Pathania M, et al. MicroRNA miR-137 regulates neuronal maturation by targeting ubiquitin ligase mind bomb-1. Stem Cells. 2010;28(6):1060-70. https://doi.org/10.1002/stem.431.

40. Hatakeyama S. TRIM family proteins: roles in autophagy, immunity, and carcinogenesis. Trends Biochem Sci. 2017:42(4):297-311. https://doi.org/10.1 016/j.tibs.2017.01.002.

41. Zhang FQ, Rao SQ, Cao HB, Zhang ZR, Wang Q, Xu Y, et al. Genetic evidence suggests posttraumatic stress disorder as a subtype of major depressive disorder. J Clin Investig. 2021;27:145942. https://doi.org/10.1172/ JCl145942 Epub ahead of print.

42. Wang $X H$, Fang $X X$, Zheng WR, Zhou JH, Song ZJ, Xu MQ, et al. Genetic support of a causal relationship between iron status and type 2 diabetes: a
Mendelian randomization study. J Clin Endocrinol Metab. 2021:dgab454. https://doi.org/10.1210/clinem/dgab454

43. Zhang FQ, Baranova A, Zhou C, Cao HB, Chen J, Zhang XR, et al. Causal influences of neuroticism on mental health and cardiovascular disease. Hum Genet. 2021;140(9):1267-81. https://doi.org/10.1007/s00439-021-02288-X.

44. Yu H, Pan R, Qi Y, Zheng Z, Li J, Li H, et al. LEPR hypomethylation is significantly associated with gastric cancer in males. Exp Mol Pathol. 2020; 116:104493. https://doi.org/10.1016/j.yexmp.2020.104493.

45. Liu M, Li F, Yan H, Wang K, Ma Y, Alzheimer's Disease Neuroimaging Initiative, et al. A multi-model deep convolutional neural network for automatic hippocampus segmentation and classification in Alzheimer's disease. Neuroimage. 2020;208:116459. https://doi.org/10.1016/j.neuroima ge.2019.116459

\section{Publisher's Note}

Springer Nature remains neutral with regard to jurisdictional claims in published maps and institutional affiliations.
Ready to submit your research? Choose BMC and benefit from:

- fast, convenient online submission

- thorough peer review by experienced researchers in your field

- rapid publication on acceptance

- support for research data, including large and complex data types

- gold Open Access which fosters wider collaboration and increased citations

- maximum visibility for your research: over $100 \mathrm{M}$ website views per year

At $\mathrm{BMC}$, research is always in progress.

Learn more biomedcentral.com/submissions 